\title{
The Other Impacts of Infectious Diseases: Socio- Cultural Roles Beyond the Scene
}

\author{
Ahed J Alkhatib ${ }^{1,2 *}$ \\ ${ }^{1}$ Department of Legal Medicine, Toxicology of Forensic Science and Toxicology, School of Medicine, Jordan Jordan \\ ${ }^{2}$ International Mariinskaya Academy, department of medicine and critical care, department of philosophy, Academician secretary of \\ department of Sociology \\ *Corresponding author: Ahed J Alkhatiib, Department of Legal Medicine, Critical care and Philosophy, Toxicology of Forensic \\ Science and Toxicology, School of Medicine, Jordan University of Science and Technology, Jordan
}

\section{ARTICLE INFO}

Received: 幽 July 08, 2019

Published: 蔧 July 15, 2019

Citation: Ahed J Alkhatib. The Other Impacts of Infectious Diseases: Socio-Cultural Roles Beyond the Scene. Biomed J Sci \& Tech Res 19(4)-2019. BJSTR. MS.ID.003335.

Keywords: Infectious Diseases; NonCommunicable Diseases; Diabetes; Toxoplasmosis; Crime; Helicobacter Pylori; Dental Caries; Viruses

\begin{abstract}
Introduction: Infectious diseases have exceeded the pathologic and clinic limitations to socio-cultural influences and have played non-classical roles inducing noncommunicable diseases.

Objectives: To review the literature regarding the possibilities of infectious diseases to play roles that may lead to socio-cultural impacts based on our previous studies and others.

Methodology: We reported our experiments in the role of infectious diseases in noncommunicable diseases.

Results: In the first experiment, we have found that about $50 \%$ of patients who underwent catheterization at King Abdulla University Hospital were positive for Chlamydia pneumonia as confirmed by ELIZA and PCR. From this study, infectious diseases led to heart diseases. The second set of experiments showed the localization of some viruses including Cytomegalovirus (CMV), and Human Papilloma Virus (HPV) in the adipose tissue of type 1 diabetic rats. This study indicated to a new possible role of inducing obesity and diabetes by viruses. The third set of experiments showed the findings of our studies regarding the impact of latent toxoplasmosis in possible association with crime. We found that there is a significant association between latent toxoplasmosis and each of physical violent actions, and crime based on seropositivity of IgM, and IgG of Toxoplasma. Other studies reported a role of latent toxoplamosis and religiosity.
\end{abstract}

Conclusions: Infectious diseases have roles exceeding known pathologic and clinical conditions that lead to non-communicable diseases and socio-cultural impacts.

\section{Introduction}

This study examines infectious diseases and their immune aspects as a measure of social interactions. The influence of infectious diseases exceeds the limits of infection and interferes with the social structure [1,2]. Infectious agents can be diagnosed with immune parameters, such as specific immunoglobulins for that agent, such as IgG and IgM [3].

\section{Heart Diseases and Infectious Impacts}

W run a study taking into consideration that atherosclerosis is more likely to have infectious origin. We studied the existence of Chlamydia pneumoniae (C. pneumoniae) among patients with coronary artery coronary (CAD). C. pneumonia has the ability to induce infection to various cells such as monocyte in circulation and individual and move from lungs into the local extra-pulmonary areas including subendothelium space within the wall of arteries. Additionally, the engagement of arterial wall requires the presence of macrophage foam cells and cholesterol as low density lipoprotein (LDL). The study included patients to be subjected for angiography. Both ELISA for IgG and PCR for genes OMP1 were carried out. ELISA testing was positive among $43.1 \%$. The results were confirmed by PCR, the prevalence of C. pneumoniae was $27.7 \%$ [4]. 


\section{Diabetes Type 1 And Infectious Perspectives}

To answer the question regarding the potential of microbial infections and the occurrence of type 1 diabetes, we conducted a study and induced type 1diabetes in rat experimental model. The following viruses Cytomegalovirus (CMV) and Human Papilloma Virus (HPV) were detected in the adipose tissues of diabetic rats. It can be concluded from these experiments that adipose tissue may play a new role in the occurrence of type 1 diabetes through retaining infectious agents rather than metabolic points of view. Previous studies have put emphasis on the potential of viruses to interfere with fatty tissue in diabetic models, particularly an avian adenovirus [5].Taken together, it is possible that viruses have roles in the obesity burden and as a result on the occurrence of diabetes; this may imply that obesity to be a carrying source of viruses which illuminates the consideration that diabetes is more likely to exceed the possibility of the metabolic views.

\section{Infectious Diseases and Community}

Due to the consideration that infectious diseases are common in the community, we have carried out a series of studies to investigate the influences of infectious diseases in social context. Infectious diseases have manifestations such as inflammatory processes on patients including cardinal signs of inflammation such as high temperature degrees [6]. Pathogens in latent stage do not produce classical clinical pictures from inflammatory point of view, and accordingly, such pathogens are not accounted for clinical outcomes. One of the examples of latent pathogens is latent toxoplasmosis by Toxoplasma gondii ( $T$. gondii). It invades the brain and remains latent for about 20 years or more and works to reprogram the brain of its host to make appropriate environmental conditions to its existence through creating changes in brain chemistry [7]. Our studies put focus in the relationship between the influence of being infected with latent toxoplasmosis and crime. Significant relationships were found between latent toxoplasmosis and violence, road traffic accidents, and crimes. In one study, we investigated the frequency of both IgG and IgM of T. gondii among prisoners who had actions of physical violence nature. It was interesting to find a significant association between latent toxoplasmosis and the status of physical violent actions $(\mathrm{p}=0.003)$ [8]. We expanded our horizon through studying another group of prisoners who were classified as murders. The results of our study revealed that latent toxoplasmosis was significantly associated with crime commitment $(\mathrm{p}=0.010)$. Furthermore, approximately $20 \%$ of crimes cases were attributed to latent toxoplasmosis [9]. We also studied the relationship between latent toxoplasmosis and road traffic accidents. The results of our study revealed that no significant relationship between latent toxoplasmosis and traffic road accidents $(\mathrm{p}=0.0828)$ [10].

\section{Latent Toxoplasmosis and The Status of Religiosity}

As previously described, microbes can influence patterns of behavior of both human and animals [11-13]. Latent toxoplasmosis has been reported through several studies to be associated with violence and aggressiveness such as suicide [14-16]. Previous studies such as the study of Panchin et al. demonstrated the ability of some pathogens to invade human brain and to induce some religious rituals for the enhancement of microbial propagation. This phenomenon is referred to as "biomeme hypothesis", and it implies that microbes incline individuals into particular religious rituals. It was interesting to be found that pathogens have the ability to influence human behaviors, and further, some religious rituals are reflected as good indicators for these influences [17].

\section{Conclusion}

The present study indicated to other dimensions of infectious diseases from various perspectives and showed further that infectious diseases have more importance than it is previously thought.

\section{References}

1. Ahed J Alkhatib (2015) Molecular Sociology: Further Insights from Biological and Environmental Aspects. DIALOGO 2 (1): 169 -172.

2. Ahed J Alkhatib (2017) The Expression of Estrogen Receptor and Bcl2 in Candida albicans May Represent Removal of Functional Barriers among Eukaryotic and Prokaryotic Cells". EC Microbiology SI.01 (2017): 20-23.

3. Ahed J Al-Khatib, Majdi Al Alawneh (2013) Exploring the relationship between the infection of C. pneumoniae and coronary artery disease. European scientific journal 9 (6): 203-221.

4. Ali Shotar, Sukaina A, Alzyoud, Ahed J Al Khatib (2015) The Impacts of Latent Toxoplasmosis on Physical Violent Actions among a sample of Jordanian inmates. Research Journal of Biological Sciences 10(4): 72-77.

5. Ali Shotar, Sukaina A Alzyoud and Ahed J AlKhatib (2015) Social Impacts of Infectious Diseases: Latent Toxoplasmosis and Crime. The Social Sciences 10(7): 1677-1681.

6. Ali Shotar, Sukaina A, Alzyoud, Ahed J AlKhatib (2016) Latent Toxoplasmosis and the Involvement in Road Traffic Accidents among a Sample of Jordanian Drivers. Research Journal of Medical Sciences 10(4): 194-198.

7. Alkhatib AJ (2018) Non-classical Roles of Microbes. PSM Microbiol 3(2): 62-63.

8. Arling TA, Yolken RH, Lapidus $\mathrm{M}$, Langenberg $\mathrm{P}$, Dickerson FB, et al. (2009) Toxoplasma gondii antibody titers and history of suicide attempts in patients with recurrent mood disorders. J NervMent Dis 197(12): 905-908.

9. Atkinson RL (2007) Viruses as an etiology of obesity. Mayo Clin Proc 82(10): 1192-1198

10. Chen L, Deng H, Cui H, Fang J, Zuo Z, et al. (2017) Inflammatory responses and inflammation-associated diseases in organs. Oncotarget 9(6): 72047218.

11. Nunn C L, Jordán F, McCabe C M, Verdolin J L, Fewell JH, et al. (2015) Infectious disease and group size: more than just a numbers game. Philosophical transactions of the Royal Society of London. Series B Biological sciences 370(1669).

12. Okusaga O, Langenberg P, Sleemi A, Vaswani D, Giegling I, et al. (2011) Toxoplasma gondii antibody titers and history of suicide attempts in patients with schizophrenia. Schizophr Res 133(1-3): 150-155.

13. Panchin AY, Tuzhikov AI, Panchin YV (2014) Midichlorians - the biomeme hypothesis: is there a microbial component to religious rituals? Biol Direct 9(1): 14

14. Pedersen MG, Mortensen PB, Norgaard-Pedersen B, Postolache TT 
(2012) Toxoplasma gondii infection and self-directed violence in mothers. ArchGen Psychiatry 69(11): 1123- 1130.

15. Petro Starokadomskyy (2014) Microbes on the edge of Occam's razor. Biology Direct 9:25.

16. Seizova, Simona, Garnham, Alexandra L, Coffey, et al. (2019) Toxoplasma Gondii Bradyzoites Elicit Transcriptional Changes in Host Cells to Prevent IFN $\gamma$-Mediated Cell Death.

\section{ISSN: 2574-1241}

DOI: 10.26717/BJSTR.2019.19.003335

Ahed J Alkhatib. Biomed J Sci \& Tech Res

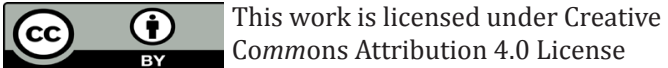

Submission Link: https://biomedres.us/submit-manuscript.php
17. Zhang Y, Träskman Bendz L, Janelidze S, Langenberg P, Saleh A, et al. (2012) Toxoplasma gondii immunoglobulin $G$ antibodies and nonfatal suicidal self-directed violence. J Clin Psychiatry 73(8):1069-1076.

$\begin{array}{ll}\text { BIOMEDICAL } & \text { Assets of Publishing with us } \\ \text { RESEARCHES } & \text { - Global archiving of articles } \\ & \text { - Immediate, unrestricted online access } \\ & \text { - Rigorous Peer Review Process } \\ \end{array}$

